\title{
DAVIES, Rosamund; SIGTHORSSON, Gauti (2013): Introducing the Creative Industries: From Theory to Practice. Londres: SAGE Publications Ltd. 280p
}

Jéssica Cantieri Taube Fagundes

Creativity is a difficult concept to define, it has an enormous rage of application and usage. One can even use creativity as a method of dealing with life and its ups and downs in a more sociological way or it can be applied as a subject to ones career meaning to essentially differ its job from any other. Professions based on creativity are rapidly growing as an important element of today's economy even though its unique condition of numerous business types makes it hard for any regulation to be satisfying and efficient. Those kind of activities are now being called "The creative industries", as Rosamund Davies and Gauti Sighthorsson point out in their book "Introducing the Creative Industries from Theory to Practice":

"The creative industries are a metaphor, which implies that creative production has been industrialized, set up in factory-like structures and managed along the same principle as the manufacture of any other mass-market goods. (...) like any other industry, the creative industries are driven by the work of people."

However this term still causes controversy, it is explored in the book as a term capable of covering a variety of activities, products and services that provide experiences. What makes Davies and Sighthorsson's book specially stimulating is that it builds the view of the creative industries from the perspective of real people working in it, exploring different cases and situations and what are their impressions on the industry. Although the book has not been translated to other languages yet and its research has been based majority on the United Kingdom reality, the content was exposed in such a way that it would be valid in any other country or market. The authors had the regard of bringing UK's patterns as a sample readers could relate to and apply in their own reality. 
The book's structure was planned to make its navigation easy, since it could be used not only as an instructive source but as a content to refer to if necessary. Therefore there are side columns with important terms and concepts explanation throughout the pages, key words are highlighted in the main text along with titles and subtitles well pointed up.

It is divided in four sections, on the first one the term "Creative Industries" is presented followed by a short introduction of creative products and services in the course of times and historical periods. Since the first section has its focus on introductory approaches, the second section can be consider the actual beginning of the book's main topic, which is to show what is happening in the industry and how people are being successful. This section differs some of the creative industry jobs by providing examples of people that work in the media business, writing business and some others, as well as pointing out their work routine. The freelancer career is the most reported, even with the efforts of the authors in trying to contemplate a lot of different kinds of creative work. Maybe, as the book 's intuit is to help professionals in the area, they thought that freelancers were most lacking information and support, nonetheless their increasing participation in economy.

In one hand the second section had its focus on the people and their work, now the third section of the book approaches the concepts around the product itself, how it is planned, categorized and delivered. They introduce not only the product as a material item but services and immaterial aspects of the creative industries that are delivered to the public. How ideas became creative products. It is refreshing their approach to experience as a product and how it is more than merely a TV show, a movie, a video game or even a theme park, it is the experience within. The authors present the example of a daily situation where friends accidentally give "spoilers" of a movie to one another and it ruins the entire perception of film, as they describe in the book, Films and so many others products are "experience goods". What is the distinction between the Harry Potter books, the movies, the Studio Tour or the Theme Park? They are all creative content and creative experiences and the users pay individually for each one of these kinds of experience.

Also in the third section, the authors feature the importance of marketing and distribution in the creative industries. It is normal to see people focusing on having ideas and creating new things, but some does not realize that is just the first step. No matter if the product is intangible or tangible, if it was produced it has to return the investment. Therefore the book explains circulation and its processes as well as pointing others examples of distribution and what could go wrong.

In the last section business models are brought as a illustration of changes in the industry, where production is vertically disintegrated while distribution remains vertically integrated. It was interesting how the authors blended more the freelancer jobs and multinational companies examples in the first chapter of this section, showing the commission process on TV and magazines. So then they display the client relationship using as a case media agencies, from briefing to public funding, loans and crowdfunding. To end up with today's economy, opening the discussion of work routines and work cultures changes, 
how open are the professionals to changes now a days? And how are they investing in "soft skills" rather than only "hard skills"? "The creative industries regularly generate job descriptions that previously did not exist." The industry is changing so fast that is likely for most of us to be working in jobs that do not exist yet, or did not exist ten years ago. So how are the professionals supposed to know what they should learn or invest on in the path of building their career? This book only tries to demonstrate what is already there and how products, business models, people and markets have been acting in the past decades. The authors make a lot of references and recommend readings, but the real solution to each case now and in the course of time has to be build is in the readers head. 